\title{
Optical properties of Al doped ZnO Nanofibers Prepared by electrospinning
}

\author{
Chan-Geun Song and Jong-Won Yoon ${ }^{\dagger}$ \\ Department of Advanced Materials and science, Dankook University, Choenan, Chungnam 330-714, Korea \\ (Received September 20, 2011) \\ (Revised October 12, 2011)
}

(Accepted October 14, 2011)

\begin{abstract}
Zinc oxide has semi-conductivity and super conductivity characteristics. It can be used optically and is applied on many areas such as gas sensor, solar cell and optical waveguide. In this paper, to improve optical characteristics of $\mathrm{ZnO}$, aluminum was added on zinc oxide. Zinc oxide and aluminum zinc oxide was fabricated as nano fiber form. $\mathrm{ZnO}$ solution was created by mixing poly vinyl pyrrolidone, ethyl alcohol, and zinc acetate. An Al doped $\mathrm{ZnO}$ was created by adding aluminum solution to $\mathrm{ZnO}$ sol. By applying these sols on electro spinning method, nano fibers were fabricated. These fibers are heat treated at 300,500 , and $700^{\circ} \mathrm{C}$ degrees and were analyzed with X-ray diffraction (XRD), X-ray photoelectron spectroscopy (XPS) and scanning electron microscopy (SEM) to examine the nano structures. TGA and DSC measurement was also used to measure the change of mass and calorie upon temperature change. The absorbance of $\mathrm{ZnO}$ and $\mathrm{Al}$-doped $\mathrm{ZnO}$ was carried out by $\mathrm{UV}$-vis measurement.
\end{abstract}

Key words $\mathrm{ZnO}$, Electrospinning, Nanofiber, Al-doping, Optical properties

\section{전기방사를 이용한 $\mathrm{Al}$ 이 첨가된 $\mathrm{ZnO}$ 나노섬유의 제조 및 광학 특성평가}

\section{송찬근, 윤종원}

단국대학교 신소재공학과, 충남, 330-714

(2011년 9월 20일 접수)

(2011년 10월 12일 심사완료)

(2011년 10월 14일 게재확정)

요 약 $\mathrm{ZnO}$ 는 반도전성과 초전도성을 나타내며 광학적으로도 독특한 재료로 가스센서, 태양전지, 광학도파관 등 여러 방면에 널리 활용되고 있다. 본 논문에서는 이러한 $\mathrm{ZnO}$ 에 $\mathrm{Al}$ 을 첨가함에 따라 광학적 특성에 어떠한 영향을 미치는지 알 아보기 위하여 $\mathrm{ZnO}$ 에 $\mathrm{Al}$ 첨가량 변화에 따른 나노구조체를 제작하여 특성을 비교하였다. $\mathrm{ZnO}$ 용액은 PVP, ethanol, zinc acetate를 이용하여 $\mathrm{Sol}$ 의 형태로 제작하였으며, $\mathrm{Al}$ 첨가용액을 넣어 $\mathrm{Al}$ 이 첨가된 $\mathrm{ZnO} \mathrm{Sol}$ 을 제작하였다. 제작된 $\mathrm{Sol}$ 을 전기 방사법을 이용하여 나노구조체를 제조하였다. 제조된 섬유들을 각각 $300,500,700^{\circ} \mathrm{C}$ 로 열처리 한 후 나노 구조체를 $\mathrm{XRD}$, $\mathrm{XPS}, \mathrm{SEM}$ 을 이용하여 분석하였다. 또한 TGA, DSC를 이용하여 온도변화에 따른 질량 및 열량의 변화를 측정하였다. UVvis를 이용하여 $\mathrm{ZnO}$ 와 $\mathrm{Al}$ 이 첨가된 $\mathrm{ZnO}$ 의 흡광도를 측정 비교하였다.

\section{1. 서 론}

$\mathrm{ZnO}$ 는 플라즈마 상태에서 화학적 안정성이 우수하고, 가격이 저렴한 재료로서 wurtzite 구조를 가지며, 자체결 함이 있는 비화학양론적 구조를 가진다. $\mathrm{ZnO}$ 는 밴드갭 에너지가 $3.2 \mathrm{eV}$ 인 n-type 화합물 반도체로서 다양한 범 위의 비저항을 갖는 재료로, 압전재료 및 반도성을 이용 한 가스센서나, 광학적 성질을 이용한 광학도파관, 태양

\footnotetext{
Corresponding author

Tel: +82-41-550-3536

Fax: +82-41-569-2240

E-mail: jwyoon@dankook.ac.kr
}

전지 등으로 응용이 기대되는 재료이다. $\mathrm{ZnO}$ 박막 제조 방법으로는 CVD, RF magnetron sputtering, Sol-Gel, DC sputtering, Spray pyrolysis, Electrospinning 등이 있다[1]. 위의 방법 중 전기방사 방법은 간단한 실험장 치를 이용하여 수백 $\mathrm{nm}$ 직경을 가지는 1 차원 나노섬유 구조를 손쉽게 제작할 수 있다는 장점으로 인하여 1990 년대부터 많은 연구들이 수행되어 왔다[2]. 전기방사된 나노섬유 웹은 매우 작은 기공들을 가지며, 필터나 센서, 보호 용 의복 등 다양한 용도로 적용이 가능하다. 전기 방사의 장점은,기능성 나노입자를 고분자 용액 또는 용 융물에 첨가 하여 전기방사함으로써, 기능성 나노섬유를 단일공정으로 비교적 용이하게 제조할 수 있다는 점이다 
[3].

본 연구에서는 전기방사법을 이용하여 $\mathrm{ZnO}$ 나노섬유 와 $\mathrm{Al}$ 이 첨가된 $\mathrm{ZnO}$ 나노섬유를 제조한 후 열처리 조 건에 따른 미세구조 및 결정상의 변화를 FE-SEM 및 $\mathrm{XRD}$ 검증을 통하여 평가하였으며, XPS에 의한 화학양 론 분석을 수행하여 최적의 합성조건 및 도핑조건을 찾 는 것을 목적으로 하며 제작된 나노섬유의 광학 특성 평 가를 목적으로 하고 있다.

\section{2. 실험방법}

$\mathrm{Al}$ 이 첨가된 $\mathrm{ZnO}$ 나노섬유는, 졸겔법을 이용하여 폴 리머 용액을 제조하고 그 용액을 전기방사를 이용하여 만든다. $\mathrm{ZnO}$ 용액의 제조 는 Zinc acetate와 증류수를 이용하여 Sol을 제조하며, Poly vinyl pyrrolidone(PVP) 과 ethanol을 이용하여 점도를 조절한다. 또한 $\mathrm{Al}$ 첨가 용액은 Aluminum acetate를 이용하여 위와 같은 방법으 로 제작한다. 이후 $\mathrm{Al}$ 용액을 $\mathrm{Zn}$ 용액에 첨가하여 각각 24시간 교반한다.

제작된 Sol을 이용하여 $10 \sim 12 \mathrm{kV}$ 의 전압과 $10 \mu \mathrm{l} / \mathrm{min}$ 의 일정한 흐름율로 바늘의 끝에서 기판까지의 거리를
유지한 채 전기방사를 하였다. 알루미늄 호일 및 SUS기 판 그리고 석영유리를 기판으로 사용하였다.

이러한 방사된 나노섬유들은 각각 $10^{\circ} \mathrm{C} / \mathrm{min}$ 의 승온속 도로 가열하여 300,500 및 $700^{\circ} \mathrm{C}$ 로 열처리 하였다.

각각의 샘플은 주사전자 현미경 $(\mathrm{SEM})$ 분석을 통하여 각각의 형태와 직경을 측정하였으며, $\mathrm{X}$ 선 회절 $\mathrm{XRD})$ 분석을 통하여 각각 샘플의 결정구조를 분석하였고, $\mathrm{X}$ 선 광전자 분광법(XPS) 분석을 통하여 $\mathrm{Al}$ 의 첨가여부를 확인하였다. 그리고 열중량 분석기(TGA) 및 시차주사 열량계(DSC)를 이용하여 온도변화에 따른 질량 및 열량 을 분석하였다. 또한 분광광도계(UV-VIS)를 이용하여 흡광도를 측정 및 비교하였다.

\section{3. 결과 및 고찰}

Fig. 1은 열처리 온도의 변화에 따른 $\mathrm{ZnO}$ 나노섬유의 형상을 $\mathrm{SEM}$ 으로 관찰한 것이다. 열처리를 하기전의 나 노섬유는 표면이 매끄럽고 균일하게 직경 약 $300 \mathrm{~nm}$ 의 섬유상을 유 지하고 있지만 열처리 온도가 각각 $300^{\circ} \mathrm{C}$, $500^{\circ} \mathrm{C}$ 로 높아짐에 따라 직경이 약 $200 \mathrm{~nm}, 150 \mathrm{~nm}$ 로 얇아지고 표면이 거칠어지는 것을 알 수 있으며, $700^{\circ} \mathrm{C}$

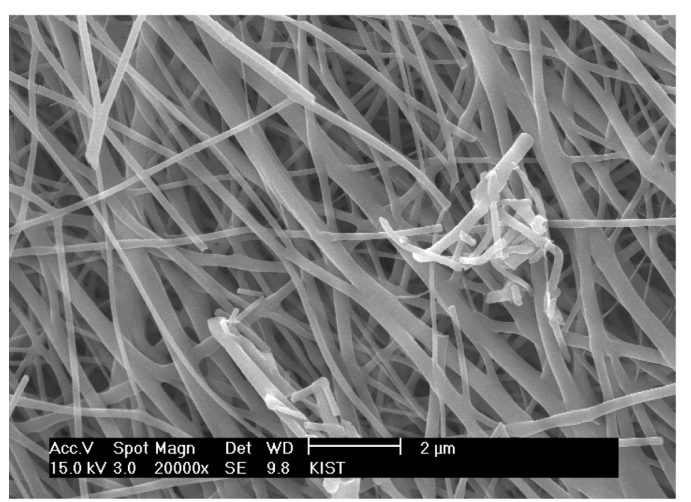

(a)

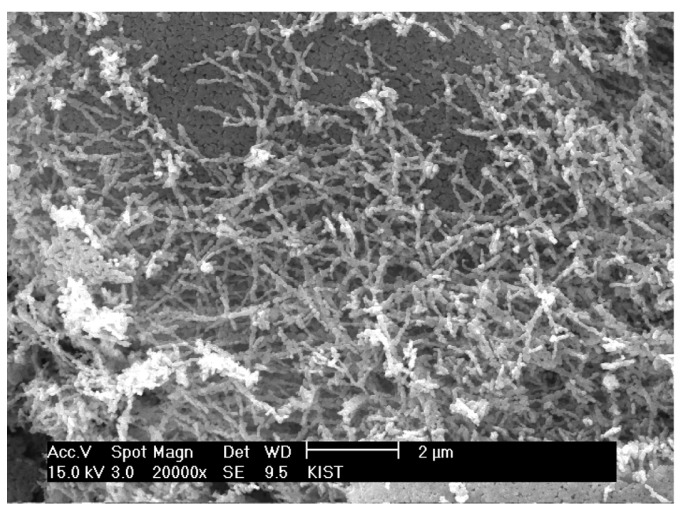

(c)

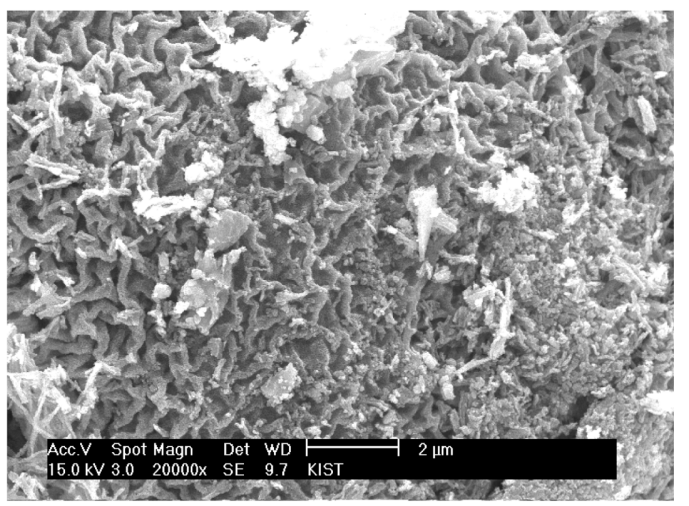

(b)

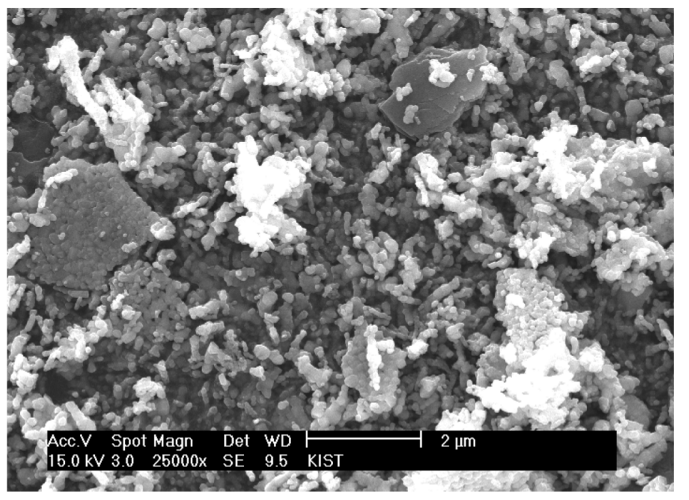

(d)

Fig. 1. SEM images of Al-doped $\mathrm{ZnO}$ nanofibers: (a) before and after heat treatment at (b) $300^{\circ} \mathrm{C}$, (c) $500^{\circ} \mathrm{C}$ and (d) $700^{\circ} \mathrm{C}$. 


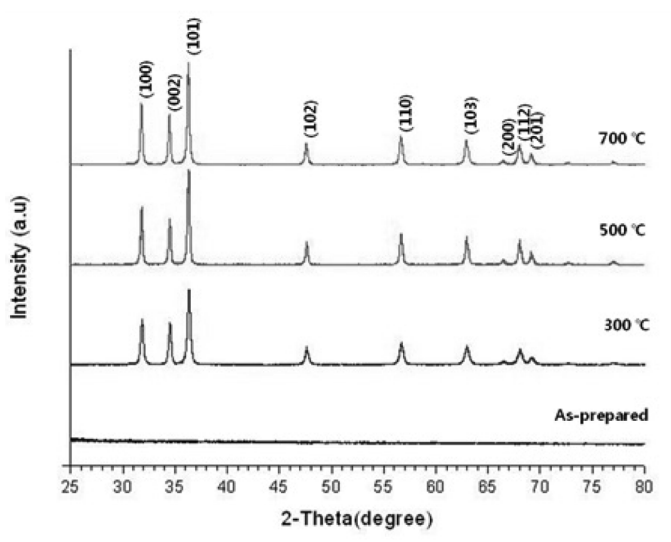

(a)

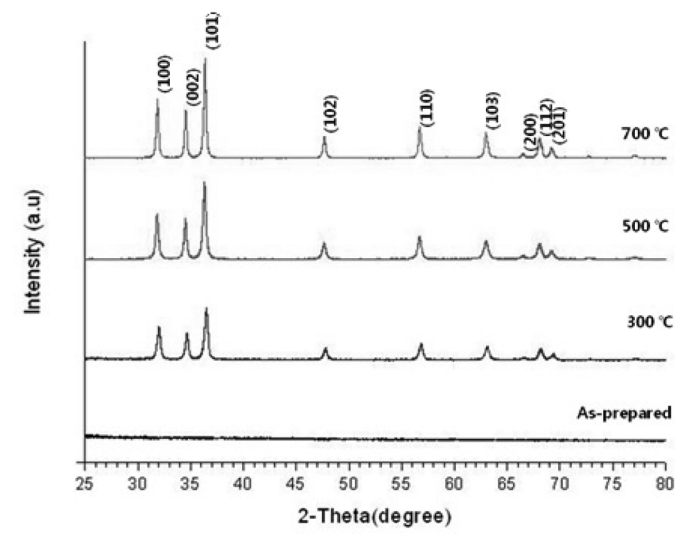

(b)

Fig. 2. XRD patterns of pure $\mathrm{ZnO}$ nanofibers (a) and 3 at\% Al-doped $\mathrm{ZnO}$ nanofibers (b).

열처리 후에는 섬유의 형상을 유지하지 못하였다.

Fig. 2는 각각 $\mathrm{ZnO}$ 나노섬유와 $\mathrm{Al}$ 이 $3 \mathrm{at} \%$ 첨가된 $\mathrm{ZnO}$ 나노섬유의 열처리 온도에 따른 $\mathrm{XRD}$ 분석 결과이 다. $\mathrm{ZnO}$ 나노섬유는 $\mathrm{XRD}$ 분석결과 Wurtzite 구조임을 알 수 있었으며, 각각의 샘플은 열처리 온도가 증가함에 따라 회절피크의 강도가 높아지는 것을 볼 수 있는 데 이것은 온도가 증가함으로써 결정화가 많이 이루어 졌음 을 알 수 있다. 또한 $\mathrm{Al}$ 이 $3 \mathrm{at} \%$ 첨가된 $\mathrm{ZnO}$ 나노섬유 의 $\mathrm{XRD}$ 분석결과에서 $\mathrm{Al}$ 의 피크가 따로 확인되지 않은 것으로 미루어 $\mathrm{Al}$ 이 치환 고용된 것으로 추정된다.

Fig. 3에서는 $700^{\circ} \mathrm{C}$ 로 열처리한 $\mathrm{ZnO}$ 나노섬유와 $\mathrm{Al}$ 이 $3 \mathrm{at} \%$ 첨가된 $\mathrm{ZnO}$ 나노섬유의 XPS 분석 결과를 나 타내고 있다. 피크 위치 보정을 위하여 $\mathrm{C} 1 \mathrm{~s}$ 의 $284.5 \mathrm{eV}$ 보정 하였다. Fig. 3(a) (c)는 각 $\mathrm{Zn} 2 \mathrm{p}, \mathrm{Al} 2 \mathrm{p}, \mathrm{O} 1 \mathrm{~s}$ 의 결 합에너지를 나타내고 있다. 순수 $\mathrm{ZnO}$ 및 $3 \mathrm{at} \%$ 의 $\mathrm{Al}$ 이 첨가된 시편모두 $\mathrm{Zn} 2 \mathrm{p}$ 의 결합 에너지는 $1022.8 \mathrm{eV}$ 로 산 화물 $\mathrm{Zn}$ 의 피크 위치로 판명되었다. $3 \mathrm{at} \%$ 의 $\mathrm{Al}$ 이 첨가 된 시편에서만 $\mathrm{Al} 2 \mathrm{p}$ 의 결합에너지의 피크를 $75.0 \mathrm{eV}$ 에 서 확인 할 수 있었다. 따라서 $3 \mathrm{at} \%$ 의 $\mathrm{Al}$ 이 첨가된 시
편에의 경우 $\mathrm{Al}$ 이 $\mathrm{ZnO}$ 에 치환 고용 되어 도핑 된 것으 로 판단된다. 본 결과는 Fig. (b)에 제시한 $3 \mathrm{at} \%$ 의 $\mathrm{Al}$ 이 첨가된 시편의 $\mathrm{XRD}$ 분석 결과에서 $\mathrm{Al}$ 피크가 나타 나지 않은 결과와 잘 일치 한다.

열처리 전의 $\mathrm{ZnO}$ 나노섬유를 $\mathrm{TGA}, \mathrm{DSC}$ 분석 한 결 과를 Fig. 4의 (a)와 (b)에 나타내었다. TGA 측정결과로 부터 $100^{\circ} \mathrm{C}$ 부근의 첫번째 하강곡선(Stage 1$)$ 은 수분이 증발하며 질량이 감소한 것이고, 두번째 하강곡선(Stage2) 은 나노섬유를 구성하고 있던 유기물질인 PVP의 탈리를 나타내며, 세번째 하강곡선(Stage3)은 잔존유기물의 탈리 에 의한 질량감소로 예상된다. $\mathrm{DSC}$ 분석결과 또한 $\mathrm{TGA}$ 의 결과와 마찬가 지로 $100^{\circ} \mathrm{C}$ 부근의 흡열피크는 수분의 증발을 나타내며, $330^{\circ} \mathrm{C}$ 와 $420^{\circ} \mathrm{C}$ 부근의 흡열피 크는 $\mathrm{PVP}$ 의 탈리를 나타내며, $460^{\circ} \mathrm{C}$ 부근의 흡열피크 는 잔존 유기물의 탈리에 의한 것으로 판명되었다[5].

Fig. 5에서는 $700^{\circ} \mathrm{C}$ 로 열처리한 $\mathrm{ZnO}$ 나노섬유와 $\mathrm{Al}$ 이 $3 \mathrm{at} \%$ 첨가된 $\mathrm{ZnO}$ 나노섬유의 $\mathrm{UV}$-vis 분석 결과이 다. $\mathrm{Al}$ 이 $3 \mathrm{at} \%$ 첨가된 $\mathrm{ZnO}$ 나노섬유의 경우 Optical Band Gap 에너지에 해당하는 파장이 $\mathrm{ZnO}$ 의 파장보다

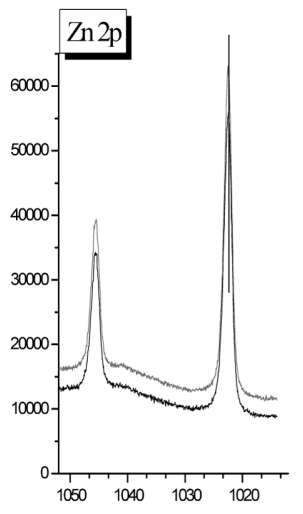

(a)

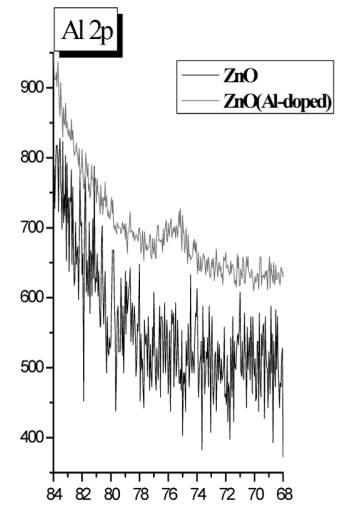

(b)

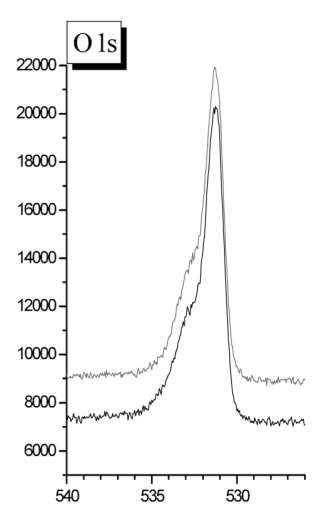

(c)

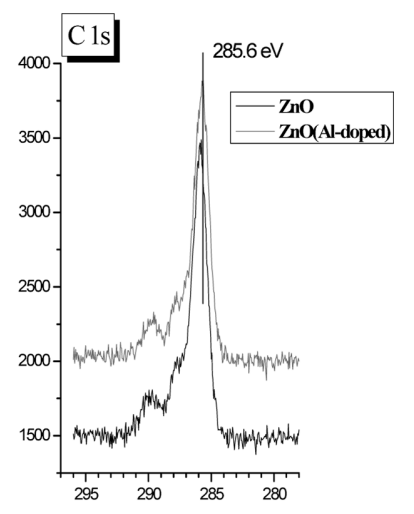

(d)

Fig. 3. X-ray photoelectron spectra: $\mathrm{ZnO}$ and 3 at\% Al-doped $\mathrm{ZnO}$. 


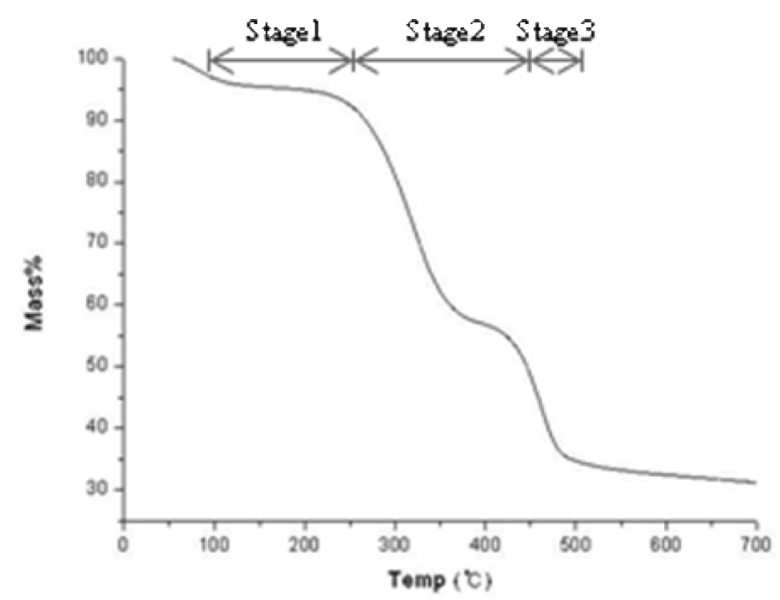

(a)

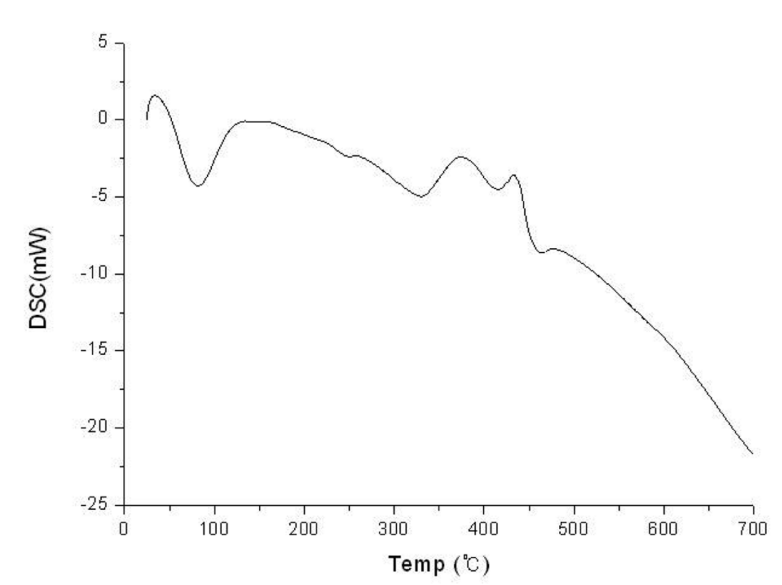

(b)

Fig. 4. TGA (a) and DSC (b) curves of $\mathrm{ZnO}$ nanofibers in the air.

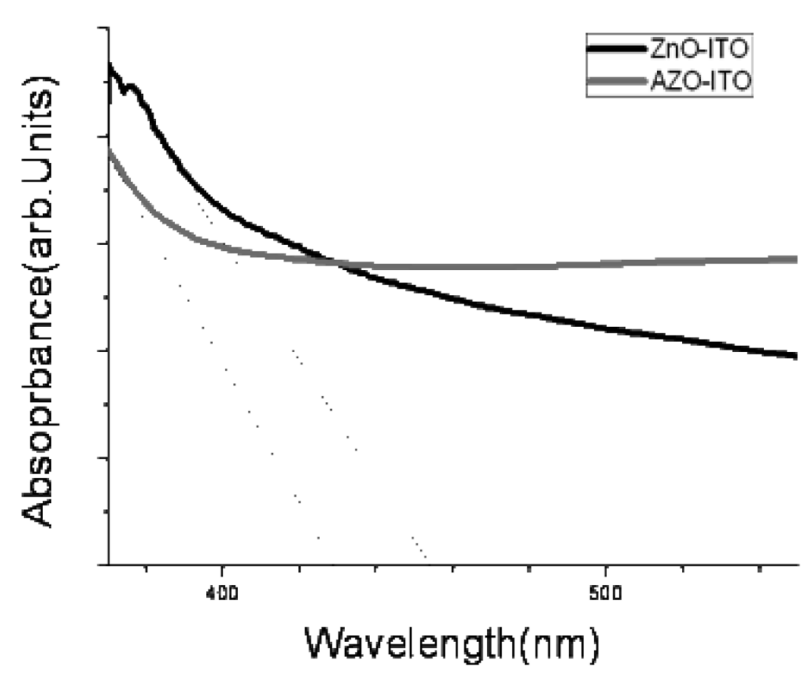

Fig. 5. Optical absorbance spectra of $\mathrm{ZnO}$ nanofibers with $\mathrm{Al}$ doped $\mathrm{ZnO}$ nanofibers.

단파장으로 $20 \mathrm{~nm}$ 이동이 된 것을 볼 수 있다. 이로써 $\mathrm{Al}$ 이 $3 \mathrm{at} \%$ 첨가됨으로써 밴드갭 에너지가 커지는 것으 로 예상된다. Burstein 이론에 따르면, $\mathrm{ZnO}$ 의 경우 donor 전자가 전도대의 하단에 위치하고 있나, $\mathrm{Al}$ 이도핑 된 경 우 Pauli의 원리에 의해 donor 준위가 이중으로 존재하 는 것을 허용하지 않으며, 또한 Optical Band Gap의 경 우 Valence Band에서 Conduction Band로 직접 천이에 기인하므로 전도대에 위치한 전자는 더 높은 에너지를 필요로 한다. Sol-gel법에 의하여 제작한 $\mathrm{Al}$ 이 첨가된 $\mathrm{ZnO}$ 박막에서도 같은 $\mathrm{Al}$ 첨가에 따라 Optical Band $\mathrm{Gap}$ 단파장 영역으로 쉬프트한 경향성을 나타내고 있어 $[9,10]$ 본 실험에서 전기방사법에 의하여 제작한 $\mathrm{Al}$ 이 도핑된 $\mathrm{ZnO}$ 나노파이버의 결과와 잘 일치 하는 결과를 나타내고있다.

\section{4. 결 론}

Zinc acetate, 물, PVP, ethanol, Aluminum acetate 등 을 출발물질로 Sol을 제작하여 전 기방사법을 이용하여 $\mathrm{ZnO}$ 나노섬유 및 $\mathrm{Al}$ 이 $3 \mathrm{at} \%$ 첨가된 $\mathrm{ZnO}$ 나노섬유를 제작하였다. 각각 열처리 후 $\mathrm{SEM}$ 분석을 한 결과 높은 온도에서 열처리 할 경우 고분자물질이 탈리되어 직경이 더욱 얇아지는 경향을 보였으며 또한 XRD 분석으로 열 처리 온도가 높을수록 결정화가 충분히 이루어짐을 알 수 있었으며, XPS 검증을 통하여 $\mathrm{Al}$ 의 첨가 유무를 밝 혀내었고, $\mathrm{TGA} / \mathrm{DSC}$ 측정을 통하여 각각 나 노섬유의 온도의 변화에 따른 질량 및 열량의 변화를 수분의 증발 및 고분자 물질의 탈리로 인한 것으로 판단하였다.

또한 UV-vis 분석을 이용하여 $\mathrm{Al}$ 이 첨가됨으로써 밴 드갭 에너지에 해당하는 파장이 단파장 쪽으로 이동하는 것으로 보아 밴드갭 에너지가 더욱 커지는 것으로 판단 되었다.

\section{감사의 글}

본 연구는 중소기업청에서 지원하는 2010년도 산학공 동기술개발사업(No.00041871-1)의 연구수행으로 인한 결과물임을 밝힙니다.

\section{참 고 문 헌}

[1] S.M. Hyun, K. Hong and B.H. Kim, "Preparation and characterization of Al-doped $\mathrm{ZnO}$ transparent conducting thin film by sol-gel processing", J. Kor. Ceramic Society. 33[2] (1996) 149. 
[2 ] D.K. Kim, S.Y. Park, J.B. Sim and Y.S. Kim, "Fabrication of $\mathrm{TiO}_{2}$ nanofiber by using electrospinning method", J. Natural Science and Technology 13 (2009) 7.

[3] K. Lee and S. Lee, "Fabrication and evaluation of electrospun $\mathrm{TiO}_{2}$ nanocompo site fibers for the development of UV-pro tective textile materials", J. Kor. Society of Clothing and Textiles 34[11] (2010) 1767.

[ 4 ] B. Zhou, Y. Wu, L. Wu, K. Jou and H. Gai, "Effects of Al dopants on the microstruc tures and optical properties of $\mathrm{ZnO}$ nanofib ers prepared by electrospinning", Physical E. 41 (2009) 705.

[ 5 ] D.Y. Lee, J.E. Cho, N.I. Cho, M.H. Lee, S.J. Lee and B.Y. Kim, "Characterization of electrospun aluminumdoped zinc oxide nanofibers", Thin Solid Film 517 (2008) 1262.

[6] A.F. Lotus, Y.C. Kang, J.I. Walker, R.D. Ramsier and G.G. Chase, "Effect of aluminum oxide doping on the structural, electrical, and optical properties of zinc oxide nanofibers synthesized by electrospinning", Materials Science and Engineering B. 15 (2010) 61.

[ 7 ] N. Bhardwaj and S.C. Kundu, "Electro spinning: A fascinating fiber fabrication technique", Biotechnology Advanced. 28 (2010) 325.

[ 8 ] N. Sankhaprom, P. Supaphol and V. Pavarajarn, "Fibrous zinc oxide prepared by combined electrospinning and solvothermal techniques", Ceramics International 36 (2010) 357.

[9] M. Wang, K.E. Lee, S.H. Hahn, E.J. Kim and S. Kim, "Optical and photoluminescent properties of sol-gel Aldoped $\mathrm{ZnO}$ thin films", Materials Letters 61 (2007) 1118.

[10] Z.Q. Xu, H. Deng, J. Xie, Y. Li and X.T. Zu, "Ultraviolet photoconductive detector based on $\mathrm{Al}$ doped $\mathrm{ZnO}$ films prepared by sol-gel method", Applied Surface Science 253 (2006) 476. 